\title{
Correlation between the suppressor of cytokine signaling- 1 and 3 and hepatitis B virus: possible roles in the resistance to interferon treatment
}

Ling-yao Du ${ }^{1,2}$, Yao-li Cui ${ }^{1,2}$, En-qiang Chen ${ }^{1,2}$, Xing Cheng ${ }^{1,2}$, Li Li ${ }^{1,2}$ and Hong Tang ${ }^{1,2^{*}}$

\begin{abstract}
Background: The suppressor of cytokine signaling family (SOCS) is an important negative regulator in the JAK-STAT signaling pathway. This study was designed to explore the correlation between SOCS-1, 2 and 3, Hepatitis B Virus (HBV) and interferon (IFN), and the relationship between SOCS and IFN therapeutic efficacy.

Methods: Four types of mouse models were established. Mice were administered with HBV replicative plasmid pHBV4.1 and IFN inducer Poly IC (Group A), pHBV4.1 (Group B), Poly IC (Group C) and saline (Group D), respectively. Liver tissues were harvested from the mice and SOCS expression was determined. Meanwhile, patients with chronic hepatitis B (CHB) were treated with pegylated interferon a-2b for 24-48 weeks. Liver biopsy was collected and the baseline SOCS expression was determined. Serum assay was performed for efficacy evaluation and correlation analysis.

Results: In animal studies, the expression level of SOCS-1 and 3 was found in the descending order of B, A, C and D. The difference between Group B and D suggested that HBV could induce SOCS. The difference between Group A and C suggested that HBV could still induce SOCS with up-regulated endogenous IFN. The difference between Group C and D suggested that ploy IC could induce SOCS, while the difference between Group B and A suggested that Poly IC might have a stronger inhibition effect for SOCS. There was no difference in SOCS-2 expression. In clinical studies, eight of twenty-four enrolled patients achieved either complete or partial therapeutic response. The expression of both SOCS-1 and 3 was higher in CHB patients than in normal controls. The baseline HBV-DNA level was positively correlated with SOCS-1 and 3. The age, viral genotype, HBVDNA, SOCS-1 and SOCS-3 were found to be related to IFN efficacy.

Conclusion: HBV could induce both SOCS-1 and 3 expression regardless of endogenous IFN level. Elevated IFN could directly up-regulate SOCS-1 and 3 expression, but it could also indirectly down-regulate SOCS-1 and 3 expression by inhibiting HBV replication. HBV might play a more important role in the SOCS up-regulation than IFN, a possible reason why patients with high HBV viral load encounter poor efficacy of IFN treatment.
\end{abstract}

Keywords: SOCS, Chronic Hepatitis B, PEG-IFN a-2b

\section{Background}

The antiviral therapy, immunomodulatory therapy and anti-inflammatory therapy are the most common treatments for patients with Chronic Hepatitis B (CHB) [1], among which the antiviral therapy with interferon (IFN) or nucleoside analogues (NA) is the key treatment $[2,3]$. INF- $\alpha$ has been widely accepted by the public for its use

\footnotetext{
*Correspondence: htang6198@hotmail.com

${ }^{1}$ Center of Infectious Diseases, West China Hospital of Sichuan University, Chengdu 610041, China

${ }^{2}$ Division of Infectious Diseases, State Key Laboratory of Biotherapy, Sichuan University, Chengdu 610041, China
}

\section{Biomed Central}

(c) 2014 Du et al.; licensee BioMed Central Ltd. This is an Open Access article distributed under the terms of the Creative Commons Attribution License (http://creativecommons.org/licenses/by/2.0), which permits unrestricted use, distribution, and reproduction in any medium, provided the original work is properly credited. as an antiviral drug. However, there are still many unknown impact factors that affect its efficacy $[4,5]$. The therapeutic efficacy of INF is mainly achieved through the complicated "IFN System" where several signaling transduction pathways are activated by the binding of INF- $\alpha$ to INF- $\alpha$ receptor (INFAR). The pathway of Janus kinase-the signal transducer and activator of transcription (JAK-STAT) is one of the typical pathways [6]. In this pathway, INF- $\alpha$ binds to INFAR-I on the membrane to form a dimer, which activates Jak-1 and Tyk2, the signal transducers in the cytoplasm, to phosphorylate and 
activate STAT1 and STAT2. Activated STAT dimer translocates into the nucleus to bind the interferonsensitive response elements (IFNSRE). Antiviral protein products are then induced to inhibit HBV-DNA transcription, promote HBV mRNA degradation and suppress HBV protein translation $[7,8]$.

The suppressor of cytokine signaling (SOCS) is induced by cytokines and is an important negative regulatory factor in the JAK-STAT signaling pathway. So far, eight members of the SOCS family have been found, which include SOCS 1-7 and cytokine inducible Src Homology 2 (SH2) containing protein (CIS). They all consist of an amino-terminus, a $\mathrm{SH} 2$ domain in the middle, and a SOCS box in carboxy-terminus [9-11]. It has been demonstrated that SOCS protein could inhibit the activity of JAKs and compete with STAT2 to bind to the phosphorylated tyrosine residues in cytokine receptors through its SH2 domain. As a result, the phosphorylation of STATs is reduced. SOCS protein could also mediate the degradation pathways of the activated signaling proteins or bind to the cytoplasmic protein tyrosine phosphatase SHP2, thus inhibiting the signal transduction [12].

Recent studies have suggested that SOCS- 1 and SOCS-3 are the negative regulators in the IFN signal transduction pathway in patients with chronic hepatitis $\mathrm{C}(\mathrm{HCV})$ infection. $\mathrm{HCV}$ core protein can induce SOCS-3 protein expression to reduce the therapeutic effect of IFN- $\alpha$ [13-15]. However, in CHB patients with IFN treatment, it's unclear whether SOCS related elements impact INF efficacy in addition to HBV genotype and viral load. Therefore, further investigation is required to determine the correlation between SOCS expression, HBV and IFN therapeutic efficacy in CHB patients. In this study, mouse models of HBV replication were established to explore the interactions between SOCS expression and HBV. The expression of SOCS family in CHB patients during IFN treatment was also investigated to explore the correlation between the therapeutic efficacy of IFN and the expression of SOCS.

\section{Methods}

\section{Animal studies}

Study design

Twenty-four healthy BALB/c male mice at 6-9 weeks of age and 18-20 g of weight were purchased from Experimental Animal Center, Sichuan University, and divided into four groups. Mice in Group A were administered with the replicative HBV plasmid DNA pHBV4.1-DNA (10 $\mu \mathrm{g}$ pHBV4.1-DNA dissolved in saline equivalent to $8 \%$ mouse body weight) via the caudal vein using highpressure injection. 24 hours after the injection, the mice were injected intraperitoneally with Poly IC at $200 \mu \mathrm{L} /$ day from day 0 to day 3. Mice in Group B were administered with an equal dose of pHBV4.1-DNA via the caudal vein as in Group A, followed by intraperitoneal injection of saline at $200 \mu \mathrm{L} /$ day from day 0 to day 3. Mice in Group C received the caudal vein high-pressure injection of an equal volume of saline and the intraperitoneal injection of Poly IC at $200 \mu \mathrm{L} /$ day. Mice in Group D received both the caudal vein high-pressure and intraperitoneal injection of saline. Six hours after the last injection, these mice were euthanized and the liver tissues were harvested.

The plasmid DNA pHBV4.1-DNA we used here is an HBV replication competent plasmid. It contains 1.3 copies of the HBV genome of serotype ayw and is capable of HBV transcription, replication and expression both in vitro and vivo $[16,17]$. It's kindly given by the Scripps Research Institute, La Jolla, CA, USA as a gift. The mouse model we established here was verified effective in our previous studies. It's a transient HBV transfection model with viral replication and expression lasting for 10 days and peaking at day 3 and day 4 . It fulfilled the applicable requirement in the study of HBV and related host factors [18].

\section{Tissue sample analysis}

Part of the mouse liver was fixed by formalin for immunohistochemical staining to detect the expression of SOCS proteins. Primary antibodies included anti-SOCS1, anti-SOCS-2 (Santa Cruz) and anti-SOCS-3 (Abcam). PBS was used as the negative control for primary antibodies. Samples with known SOCS expression were used as the positive controls. As the SOCS proteins would be stained brown, positive sample was defined as those with stained particles present in the cytoplasm, or with stained cytoplasm. Two pathologists with no prior knowledge of the study were asked to score the tissue sections according the Axiotis score standard. The percentage of positive cells and intensity of positive staining scored as follows:

\section{Percentage score}

$0=0 \sim 10 \%$ positive cells;

$1=11 \sim 25 \%$ positive cells;

$2=26 \sim 50 \%$ positive cells;

$3=51 \sim 75 \%$ positive cells;

$4=76 \sim 100 \%$ positive cells.

\section{Intensity score}

$$
\begin{aligned}
& 0=\text { no colour } \\
& 1=\text { yellow; } \\
& 2=\text { brown } \\
& 3=\text { tan } .
\end{aligned}
$$

The sum of the percentage score and intensity score equaled the final score if there was no difference in two 
pathologists' opinions. Or the mean of two sum scores would equal the final score [19].

The remaining liver tissue was put in liquid nitrogen immediately after the harvest and stored at $-70^{\circ} \mathrm{C}$. Tissues were ground into powder in liquid nitrogen. Total RNAs were extracted from the ground liver tissue and reversely transcribed into total CDNA by RT-PCR amplification. The sequences of mouse SOCS-1, SOCS-2, SOCS-3 and GAPDH genes were amplified from cDNA for semiquantitative analysis. Protein samples extracted from liver powder were analyzed using western blotting to evaluate the expression of SOCS proteins.

\section{Clinical studies}

\section{Study design}

All human subjects enrolled should meet the criteria including qualified age from eighteen to sixty-five years old, free of antiviral and immunomodulating treatment

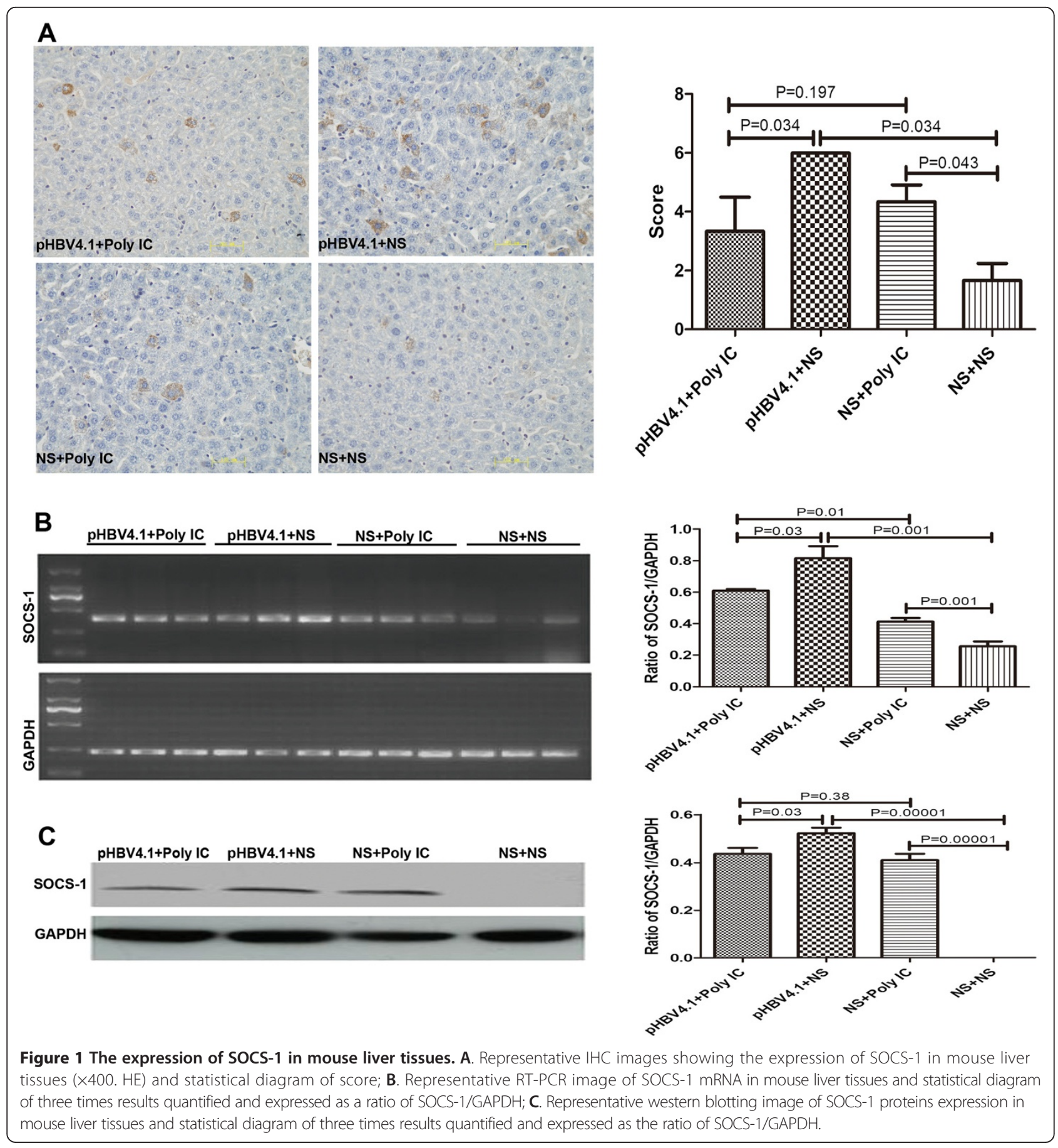


in the past six months, negative pregnancy test in female in the past 24 hours and effective contraception in both sexes during the study. They should also have positive serum HBsAg for more than 24 weeks, elevated serum HBV-DNA at more than $5 \times 10^{5}$ copies $/ \mathrm{ml}$ and twice elevated ALT between 2-10 ULN in the past 6 months. All subjects were provided with written informed consent.

The exclusion criteria included lactating women, decreased albumin at less than $3.5 \mathrm{~g} / \mathrm{L}$, extended prothrombin time for more than $4 \mathrm{~s}$, elevated serum bilirubin at more than $34 \mathrm{umol} / \mathrm{L}$, decreased neutrophile granulocytes at less than $1.5 \times 10^{9} / \mathrm{L}$, decreased platelets at less than $9.0 \times 10^{12} / \mathrm{L}$, coinfection with other hepatitis viruses and accompaniment of diabetes, thyroid dysfunction, autoimmune diseases and psychological issues.

After the enrollment, all human subjects were subcutaneously administered with pegylated interferon $\alpha-2 b$ (Peg-Intron $^{\mathrm{Tm}}$, Schering Plough, USA), with the dosage and duration varied based on the individual weight, and both personal choice and therapeutic response, respectively. The observation lasted for 48 weeks and had little impact on the conventional medical course. All subjects accepted physical examination, serum assay and liver biopsy before the treatment. At Week 12, 24 and 48 during the treatment only physical examination and serum assay were performed for therapeutic response evaluation.

\section{Sample analysis}

The liver tissue from the human subjects was examined by immunohistochemistry to evaluate the expression of SOCS family. Normal liver tissue sample was obtained from the tissue bank of West China Hospital, SCU. As mentioned before, the SOCS proteins would be stained brown as well. Samples with stained particles in the cytoplasm were defined as positive samples. The expression level of SOCS were also scored by the two pathologists mentioned before.

The serum samples collected at each medical assessment were detected for HBV-DNA quantification (Lightcycler-480, Roche, Switzerland), serum makers of HBV infection (Alisei Quality System, RADIM, Italy), liver and kidney function (Modular EVO, Roche, Switzerland) and prothrombin time (Sysmex CA-7000 Systems, Sysmex, Japan). The human subjects also received routine blood and urine examination and electrocardiogram. According to the therapeutic efficacy, those with complete or partial virological, serological or biochemical responses were assigned into the response group, while the rest were assigned into the non-response group.

\section{Statistical analysis}

Five different areas of each liver tissue section after immunohistochemical staining were scored and the RTPCR and western blotting were repeated three times. The result of RT-PCR amplification was semi-quantified by a professional image analysis software Image Pro Plus 4.5 (Media Cybernetics Inc, Silver Spring, MD,USA). The outcome of western blotting was semi-quantified by Image J, a public domain Java image processing program inspired by NIH Image for the Macintosh. All data were used for statistical analysis. Measurement data were tested for normality and presented as mean \pm standard deviation. Statistical analysis was performed by t test, $\mathrm{x}^{2}$ test, and Wilcoxon and Spearman's rank correlation test for measurement data, enumeration data, and ranked data, respectively. Logistic regression was used to determine the factors that would affect the efficacy of PEGIFN treatment in the CHB patients. All statistical analysis
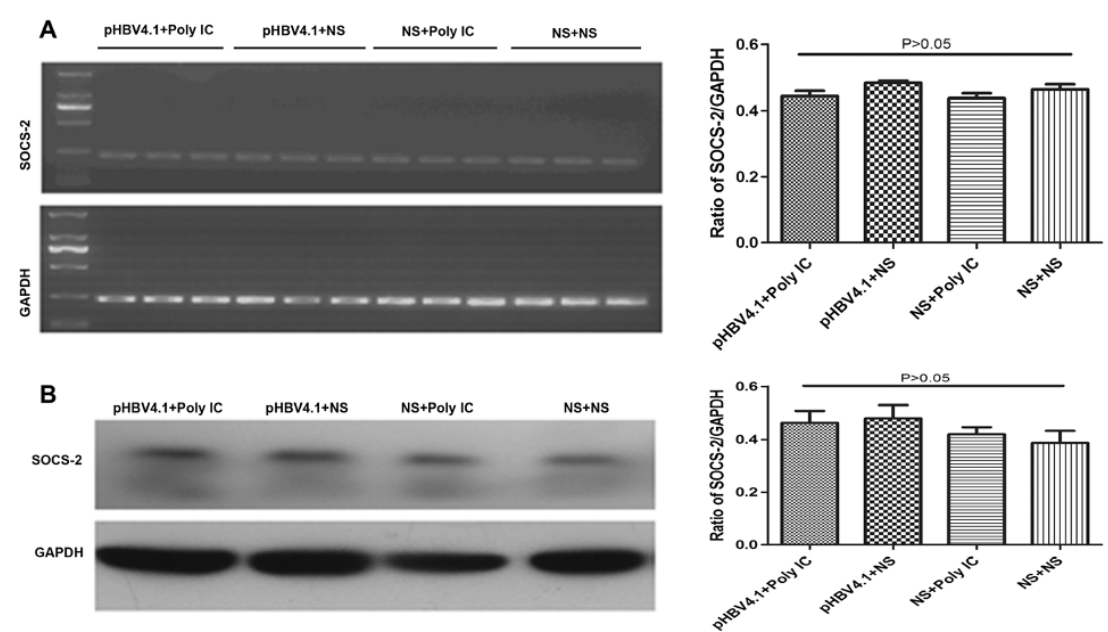

Figure 2 The expression of SOCS-2 in mouse liver tissues. A. Representative RT-PCR image of SOCS-2 mRNA in mouse liver tissues and statistical diagram of three times results quantified and expressed as a ratio of SOCS-2/GAPDH; $\mathbf{B}$. Representative western blotting image of SOCS-2 proteins expression in mouse liver tissues and statistical diagram of three times results quantified and expressed as the ratio of SOCS-2/GAPDH. 
was performed using Stata 10.0 and $\mathrm{p}<0.05$ was defined as significant difference.

\section{Ethics statement}

This study was approved by both the Laboratory Animal ethics committee of Sichuan University and the West China Hospital Ethics Committee. Written informed consents were obtained from all patients before we carried out the liver biopsy.

\section{Results}

Animal studies

Expression of SOCS-1 in liver tissues

In this study, four groups of mice were administered with HBV replicative plasmid pHBV4.1 followed with IFN inducer Poly IC (Group A), pHBV4.1 (Group B), Poly IC (Group C) and saline (Group D), respectively. SOCS-1 expression was found in all four groups with the SOCS-1 expression level in descending order from

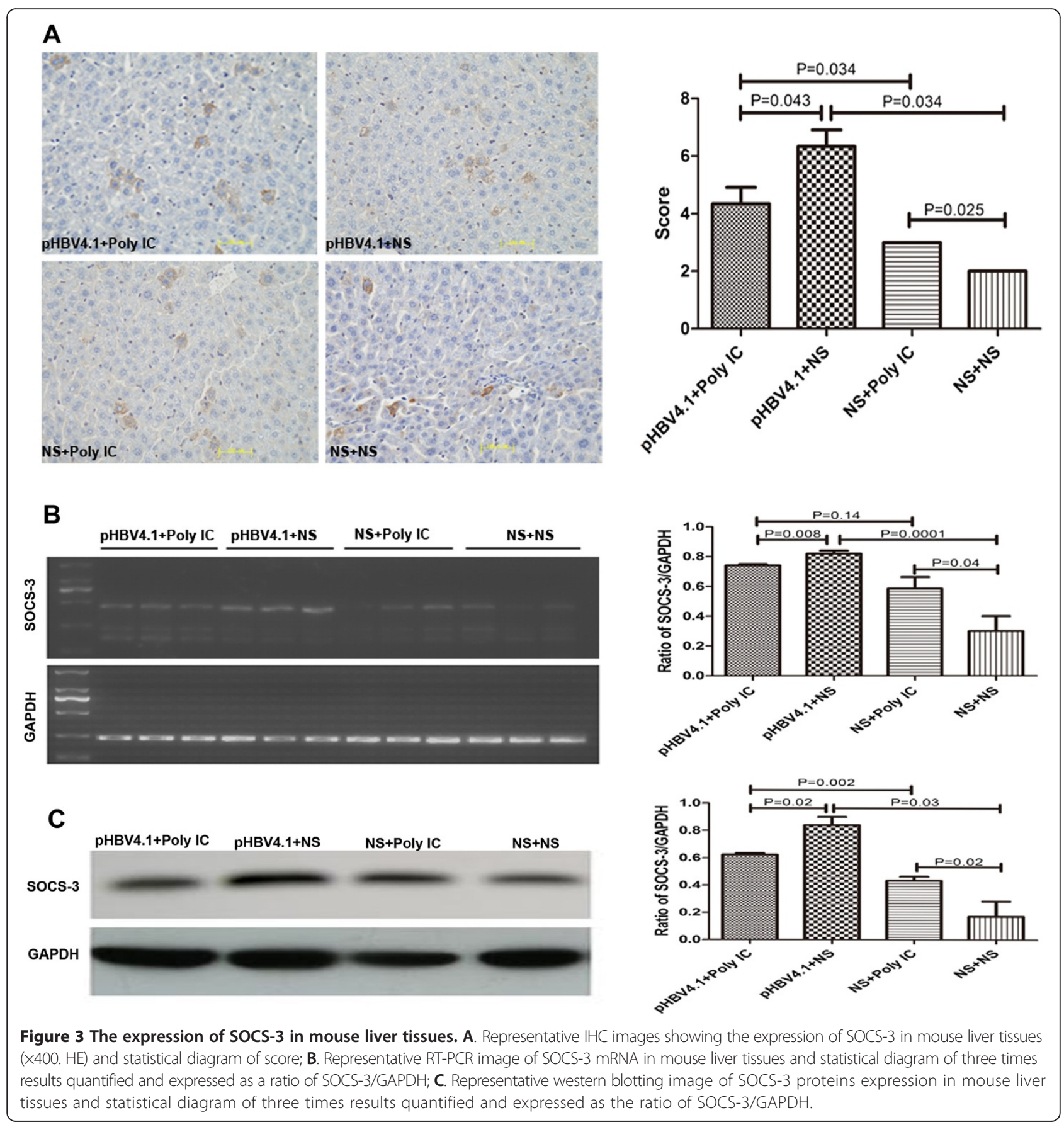


Table 1 General information of the enrolled 24 CHB patients

\begin{tabular}{cc}
\hline & Patients $\mathbf{(} \mathbf{n} \mathbf{2 4})$ \\
\hline Age (years) (Mean \pm SD) & $25.54 \pm 8.08$ \\
Gender (Male/Female) & $17 / 7$ \\
Gene Type (A/B/C) & $1 / 14 / 9$ \\
HBeAg (+/-) & $24 / 0$ \\
HBeAb (+/-) & $0 / 24$ \\
ALT (IU/L) & $224.79 \pm 95.82$ \\
AST (IU/L) & $107.00 \pm 62.45$ \\
ALB (g/L) & $36.98 \pm 2.21$ \\
TBIL (mg/dL) & $18.50 \pm 11.57$ \\
CHE (U/L) & $5857.50 \pm 623.08$ \\
INR for PT & $2.26 \pm 0.57$ \\
HBV DNA level (lg IU/ml) & $17.17 \pm 1.84$ \\
\hline
\end{tabular}

groups $\mathrm{B}, \mathrm{A}, \mathrm{C}$, to $\mathrm{D}$ as shown by immunohistochemistry, RT-PCR, and western blotting (Figure 1). The expression of SOCS-1 in Group B was significantly higher than that in Group D, suggesting that HBV could induce the expression of SOCS-1. The expression difference between Group A and C suggested that HBV could still induce SOCS with up-regulated endogenous IFN. The expression in Group $C$ was significantly higher than that in Group D, suggesting that after the direct up-regulation of endogenous IFN, SOCS-1 expression might be upregulated via some negative feedback pathway. The expression in Group B was significantly higher than that in Group A, suggesting that Poly IC might not only mediate the up-regulation of SOCS-1 via increasing endogenous IFN level to inhibit HBV replication, but also have a stronger inhibiting effect than its inducing ability.

\section{Expression of SOCS-2 in liver tissues}

There was no significant difference in SOCS-2 expression levels in all groups as determined by RT-PCR and western blotting (Figure 2), suggesting that the expression of SOSC-2 in mouse liver was affected by neither HBV nor Poly IC.

\section{Expression of SOCS-3 in liver tissues}

Consistent with the expression of SOCS-1, SOCS-3 positive cells were found in all groups using immunohistochemistry. The expression level of SOCS-3 was in the descending order of $\mathrm{B}>\mathrm{A}>\mathrm{C}>\mathrm{D}$ (Figure 3 ), same as that of SOCS-1. These results suggested that the expression of SOCS-3 and SOCS-1 was similarly mediated by HBV and Poly IC.

\section{Clinical studies \\ Subjects}

Twenty-four subjects, including 17 female and 7 male, were enrolled for clinical observation. The average age was 25.54 years old. Detailed patient information was listed (Table 1).

\section{Therapeutic response to PEGINF $a-2 b$ in CHB patients}

Fourteen patients $(14 / 24)$ received 24 weeks' treatment, and among them 5 achieved either complete or partial therapeutic response according to the judgmental criteria of the therapeutic responses in subjects. Among these 5 patients, 3 achieved HBeAg seroconversion. Another ten patients $(10 / 24)$ received 48 weeks' treatment, and among them 3 achieved $\mathrm{HBeAg}$ seroconversion. The 8 patients who achieved either complete or partial therapeutic response were assigned into the responder group, while the remaining 16 patients were assigned into the non-responder group (Table 2).

\section{Expression of SOCS-1, 2 and 3 in the liver tissue of normal controls and $\mathrm{CHB}$ patients before treatment}

Both SOCS-1-positive and SOCS-3 positive cells were observed in the liver tissues of the $\mathrm{CHB}$ patients from both the responder and non-responder groups. SOCS-1 and SOCS-3 were mainly found in the cytoplasm of the hepatocytes. In contrast, only a trace of SCOS-3 was found in the liver tissues from the normal controls (Figure 4). In addition, there was a significant difference in the expression level of both SOCS-1 and SOCS-3 between the responder and non-responder groups before the treatment. The expression of SOCS1 and SOCS-3 was higher in the non-responder group than in the responder group. SOCS-2 was not detected in any of the liver tissues examined.

\section{Factors affecting the therapeutic efficacy}

Four serum assays representing the hepatic function were performed before the treatment. Results were analyzed for correlation with SOCS-1 and SOCS-3 using Spearman Rank Correlation Test. Only the baseline HBV-DNA level was positively correlated with SOCS-1 and SOCS-3 $(\mathrm{p}<0.05)$, while none of the ALT, AST or

Table 2 The therapeutic response in CHB patients after treatment.

\begin{tabular}{|c|c|c|c|c|}
\hline \multirow{2}{*}{$\begin{array}{l}\text { Treatment } \\
\text { course }\end{array}$} & \multicolumn{2}{|c|}{ Responders $(\mathrm{N}=8)$} & \multicolumn{2}{|c|}{ Non-responders $(\mathrm{N}=16)$} \\
\hline & HBeAg seroconversion & Non-HBeAg seroconversion & HBeAg seroconversion & Non-HBeAg seroconversion \\
\hline 24 weeks & 3 & 2 & 0 & 9 \\
\hline 48 weeks & 3 & 0 & 0 & 7 \\
\hline
\end{tabular}




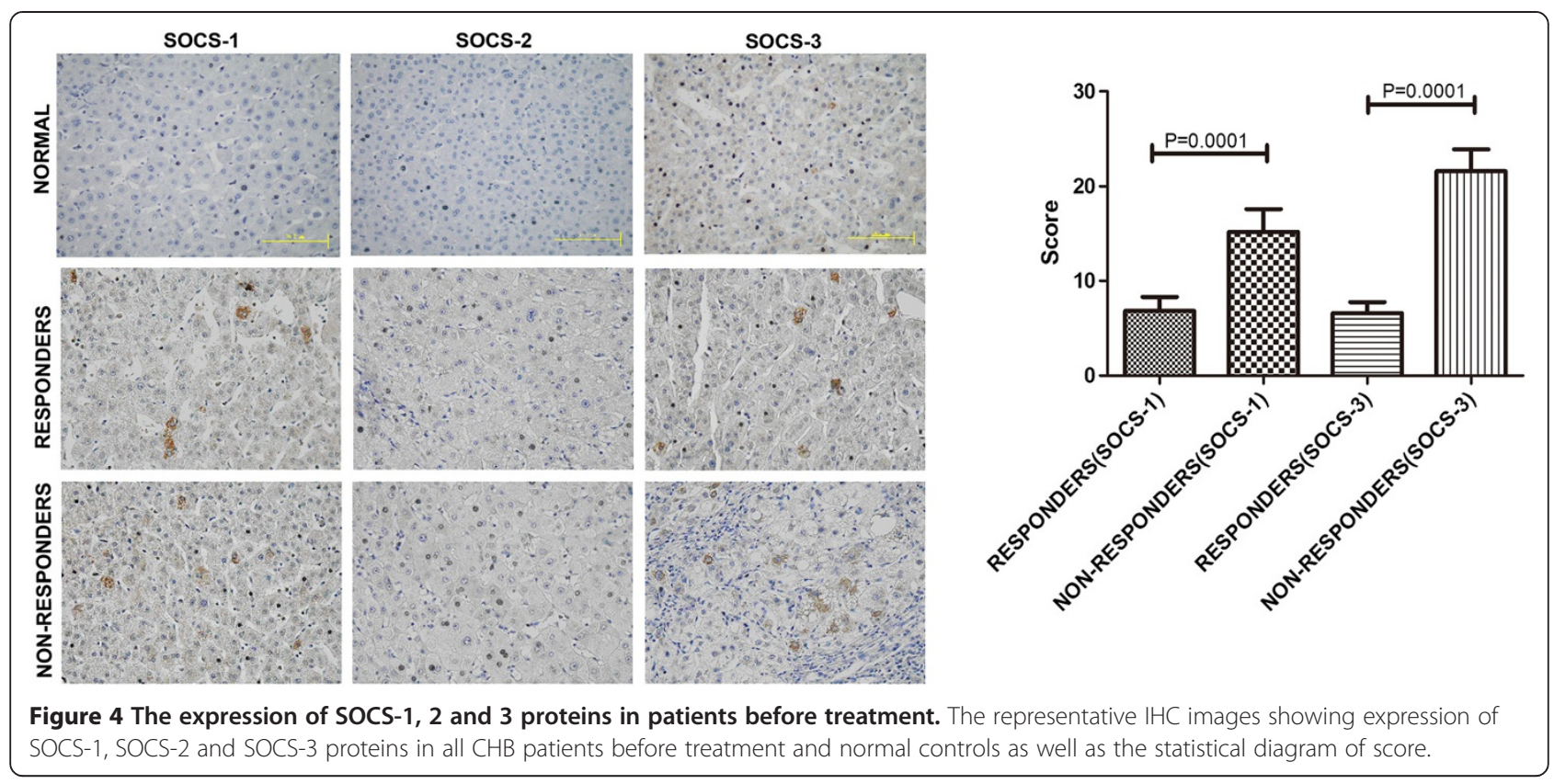

TBIL levels showed significant correlation with SOCS-1 or SOCS-3 (Table 3).

To investigate the factors which might affect the therapeutic efficacy of PEGINF $\alpha-2 b, 15$ possible factors including SOCS-1 and SOCS-3 expression level were chosen for the univariate analysis. Five factors showed significant differences between the responder and nonresponder groups, suggesting that SOCS-1 and SOCS-3, in addition to the gender, viral genotype and HBV-DNA, might impact the therapeutic response (Table 4).

Logistic regression was used to determine the correlation between the 15 factors. Five variables including gender, viral genotype, HBV-DNA, SOCS-1 and SOCS-3 were admitted into the regression model (Table 5). To prove the sensitivity and specificity of the model, the receiver operating characteristic curve (ROC curve) and cut-off point were calculated. The area under the ROC curve in this logistic regression model was $82.68 \%$ and the cut-off point was 0.50 , suggesting that the model was valid.

\section{Discussion}

CHB patients usually encounter poor therapeutic response with IFN treatment. Therefore, we set to determine whether HBV might influence the efficacy via some negative cytokine regulators. The JAK/STAT pathway is the most important antiviral signaling transduction pathway of IFN, and SOCS proteins induced by cytokines are the key negative regulating proteins in the JAK/STAT pathway. By inhibiting the activity of JAK and competitively binding to the phosphorylated tyrosine residues in cytokine receptors, SOCS proteins reduce the phosphorylation of STATs. SOCS proteins also act as adaptor molecules to guide the active cell signals to biodegradation pathway [10]. Recently the SOCS-3 protein induced by HCV core protein has been shown to be important for $\mathrm{HCV}$ absconding from host INF [20,21]. However, there are only a few studies on the correlation between HBV and SOCS proteins, which focus on single HBV protein such as $\mathrm{HBx}$ protein. $\mathrm{HBx}$ has been shown to affect the JAK/STAT pathway in the transfected hepatocytes [22,23]. The subcellular mislocalization of the mutant HBx has been found to up-regulate STAT3 activation, resulting in STAT1 inhibition and SOCS-1 and SOCS-3 expression silencing. In the HBV-related hepatocellular carcinoma, the dysregulation of STAT/ SOCS signaling is involved in the hepatocarcinogenesis [24-26].

Table 3 The correlation between SOCS family, liver function and HBVDNA

\begin{tabular}{cccccc}
\hline & & \multicolumn{2}{c}{ SOCS-1 } & & \multicolumn{2}{c}{ SOCS-3 } \\
\cline { 3 - 5 } Item & Mean \pm SD & Correlation & $\boldsymbol{P}$ value & Correlation & P value \\
\hline ALT (IU/L) & $224.79 \pm 95.82$ & -0.29 & 0.17 & -0.33 & 0.11 \\
AST (IU/L) & $107.00 \pm 62.45$ & -0.17 & 0.42 & -0.20 & 0.36 \\
TBIL (mg/dL) & $20.10 \pm 11.24$ & 0.07 & 0.74 & -0.17 & 0.44 \\
HBV DNA level & $17.17 \pm 1.84$ & 0.49 & 0.03 & 0.59 & 0.002 \\
\hline
\end{tabular}


Table 4 Univariate analysis of the factors affecting IFNa$2 b$ therapeutic efficacy

\begin{tabular}{|c|c|c|c|c|}
\hline & $\begin{array}{c}\text { Responders } \\
(\mathrm{n}=\mathbf{8})\end{array}$ & $\begin{array}{l}\text { Non-responders } \\
(n=16)\end{array}$ & $x^{2} / t / U$ & $P$ values \\
\hline $\begin{array}{l}\text { Age (years) } \\
\text { (Mean } \pm S D \text { ) }\end{array}$ & $23.75 \pm 5.60$ & $25.50 \pm 9.45$ & -0.48 & 0.64 \\
\hline $\begin{array}{l}\text { Gender (Male/ } \\
\text { Female) }\end{array}$ & $7 / 1$ & $6 / 10$ & - & 0.03 \\
\hline $\begin{array}{l}\text { Genotype } \\
\text { (A/B/C) }\end{array}$ & $0 / 6 / 2$ & $1 / 3 / 12$ & 7.29 & 0.03 \\
\hline HBeAg (+/-) & $8 / 0$ & $16 / 0$ & - & - \\
\hline HBeAb (+/-) & $0 / 8$ & $0 / 16$ & - & - \\
\hline $\mathrm{ALT}(\mathrm{IU} / \mathrm{L})$ & $251.50 \pm 108.03$ & $205.19 \pm 94.44$ & -1.03 & 0.31 \\
\hline AST (IU/L) & $106.63 \pm 36.92$ & $107.19 \pm 73.09$ & -0.02 & 0.98 \\
\hline ALB $(g / L)$ & $37.95 \pm 1.48$ & $36.49 \pm 2.39$ & 1.57 & 0.13 \\
\hline TBIL (mg/dL) & $24.27 \pm 13.63$ & $25.62 \pm 9.59$ & -0.28 & 0.78 \\
\hline CHE (U/L) & $6218.50 \pm 477.86$ & $6677.25 \pm 620.29$ & -1.83 & 0.08 \\
\hline CREA (mg/dL) & $72.11 \pm 62.02$ & $67.49 \pm 9.55$ & 0.30 & 0.77 \\
\hline INR for PT & $2.20 \pm 0.41$ & $2.02 \pm 0.50$ & 0.88 & 0.39 \\
\hline HBV DNA level & $15.34 \pm 1.29$ & $18.09 \pm 1.32$ & -4.85 & 0.001 \\
\hline SOCS-1 & $5.13 \pm 1.89$ & $15.38 \pm 3.65$ & -7.40 & 0.001 \\
\hline sOCS-3 & $6.75 \pm 1.58$ & $20.63 \pm 3.24$ & -11.37 & 0.001 \\
\hline
\end{tabular}

It was found that SOCS-3 expression increased in liver specimens from patients with $\mathrm{CHB}$ and was positively correlated with the severity of inflammation. Same result was also demonstrated in the cell culture. However, the change of SOCS-1 level was not observed [27]. In our animal studies, the change of the two SOCS proteins was observed. The expression level of SOCS-1 and
SOCS-3 proteins varied in different groups. The higher expression in Group B (pHBV4.1) as compared to Group $\mathrm{D}$ (NS) suggested that HBV induced the expression of SOCS-1 and SOCS-3 proteins. Poly IC is a well-known inducer of the endogenous IFN. Therefore, the higher expression of SOCS in Group A (pHBV4.1 + Poly IC) than in Group C (Poly IC) suggested that HBV could still induce SOCS expression with up-regulated endogenous IFN. Moreover, the expression level in Group $\mathrm{C}$ was higher than in Group D, suggesting that Poly IC might induce the up-regulation of the endogenous IFN, and then as a negative cytokine in IFN pathway, induce the expression of SOCS-1 and SCOS-3 via some negative feedback pathway. As HBV and Poly IC were both inducers, the expression level in Group A was supposed to be higher. However, IFN is an inhibitor for HBV. HBV inhibition-mediated decrease in SOCS-1 and SOCS3 expression might be stronger than IFN up-regulation mediated increase in SOCS-1 and SOCS-3 expression, leading to the higher expression level in Group B. The expression of SOCS-2 protein was not significantly different among all groups, suggesting that HBV and Poly IC couldn't affect SOCS-2 expression.

In previous clinical studies on the IFN treatment in $\mathrm{CHB}$ patients, the genotype and viral load of HBV were considered as the key indicators for INF therapeutic efficacy. Although many studies have focused on HBV, only a few focus on the host factors that might affect the INF therapeutic efficacy $[4,28,29]$. It has been reported previously that SOCS-1 and SOCS-3 proteins could downregulate the INF therapeutic efficacy as negative regulators in the IFN signaling pathway in $\mathrm{CHC}$ patients, and the

Table 5 Multivariate analysis of the factors affecting IFNa-2b therapeutic efficacy

\begin{tabular}{lcccccc}
\hline Prognostic factors & Regression coefficent & Standard error & $\boldsymbol{Z}$ value & $\boldsymbol{P}$ value & OR value & 95\% confidence interval \\
\hline Age & 1.03 & 0.77 & 1.33 & 0.18 & 2.80 & {$[-0.48 \sim 2.54]$} \\
Gender & 0.32 & 0.55 & 0.58 & 0.03 & 1.37 & {$[0.75 \sim 1.39]$} \\
Genotype (A/B/C) & 0.96 & 0.27 & 3.51 & 0.04 & 2.62 & {$[0.73 \sim 1.50]$} \\
HBeAg (+/-) & 0.86 & 0.31 & 2.80 & 0.75 & 2.37 & {$[-0.26 \sim 1.47]$} \\
HBeAb (+/-) & -0.80 & 0.27 & -2.92 & 0.63 & 0.45 & {$[-1.34 \sim 1.27]$} \\
ALT (IU/L) & -0.58 & 0.32 & -1.82 & 0.07 & 0.56 & {$[-1.21 \sim 0.05]$} \\
AST (IU/L) & -1.93 & 0.34 & -5.65 & 0.96 & 0.14 & {$[-2.60 \sim 1.26]$} \\
ALB (g/L) & 0.17 & 0.77 & 0.22 & 0.83 & 1.62 & {$[-1.35 \sim 1.68]$} \\
TBIL (mg/dL) & 0.001 & 0.004 & 1.40 & 0.16 & 1.00 & {$[1.00 \sim 1.24]$} \\
CHE (U/L) & 2.18 & 1.23 & 1.78 & 0.08 & 8.91 & {$[0.80-99.22]$} \\
CREA (mg/dL) & -0.04 & 0.03 & -1.55 & 0.12 & 0.96 & {$[0.91 \sim 1.01]$} \\
INR for PT & -0.003 & 0.001 & -1.94 & 0.05 & 0.99 & {$[0.99 \sim 1.00]$} \\
HBV-DNA & 0.003 & 0.001 & 2.03 & 0.04 & 1.00 & {$[1.00 \sim 1.01]$} \\
SOCS-1 & -3.67 & 1.49 & -2.47 & 0.03 & 0.03 & {$[0.01 \sim 0.47]$} \\
SOCS-3 & -2.50 & 1.24 & -2.02 & 0.04 & 0.08 & {$[0.01 \sim 0.93]$} \\
Cons & -0.11 & 4.07 & -0.03 & 0.98 & - & -
\end{tabular}


overexpression of SOCS-3 protein could be used for the prognosis of $\mathrm{CHC}$ patients with INF treatment. Therefore, it is possible that SOCS-1 and SOCS-3 proteins could similarly affect the therapeutic efficacy in $\mathrm{CHB}$ patients by negatively regulating IFN signaling transduction. Recently, it has been shown that plasmacytoid dendritic cells (pDCs) treated with HBsAg present a defect in INF- $\alpha$ secretion due to HBsAg-mediated upregulation of SOCS-1 expression [30], which might partially explain the HBV immune escape and persistent infection. In our clinical observation, under a natural HBV infection status, same results were obtained regarding the change of SOCS-1 and SOCS-3 as in the animal models. The higher expression of SOCS-1 and SOCS-3 in liver tissues of CHB patients compared to the normal controls again demonstrated the potential ability of HBV to induce SOCS-1 and SOCS-3. In addition, we also found higher expression of the two SOCS proteins in liver tissues in the responders as compared to the non-responders, suggesting that the efficacy of INF treatment might be impacted by the expression level of SOCS-1 and SOCS-3 proteins before the treatment. Negative correlation between the expression of SOCS proteins before treatment and the INF therapeutic efficacy was found using both one-way ANOVA and multivariate analysis. These results might explain why the patients with higher expression of SOCS-1 and SOCS-3 proteins in liver before treatment showed INF resistance, and the severity was consistent with the expression level.

HBx and HBsAg are able to change the expression of some SOCS proteins $[24,30]$. We showed that the most important medical indicator, HBVDNA, did interact with SOCS expression in CHB patients. In addition to the expression differences between the $\mathrm{CHB}$ patients and the normal controls, the expression of SOCS proteins also varied in patients with different viral load, which was positively correlated with the expression level of SOCS-1 and SOCS-3 proteins. The higher the viral load, the more expression of SOCS-1 and SOCS-3 in the liver tissues, and the more effective in their ability to block IFNinduced signaling pathway. Together with the results from animal studies, our data explained why the viral load is the most important indicator for IFN therapeutic efficacy predication. HBV induced the expression of SOCS proteins, which then inhibited IFN signaling transduction pathway. As a result, IFN antiviral efficacy was decreased. Thus, these results provided the theoretical foundation for studying the relationship between SOCS proteins in $\mathrm{CHB}$ patients before treatment and IFN therapeutic efficacy, and explained why HBV appeared to play a more important role than IFN in SOCS up-regulation. However, since the transfection efficacy of hydrodynamic delivery in this mouse model in vivo was too low, our findings need to be confirmed with further investigations.
In conclusion, HBV could induce SOCS-1 and SOCS-3 expression regardless of the level of the endogenous IFN. The elevated IFN would directly up-regulate SOCS- 1 and SOCS-3 via some negative feedback pathway, and indirectly down-regulate SOCS-1 and SOCS- 3 by inhibiting HBV. However, HBV played a more important role than IFN in SOCS up-regulation, a possible reason why patients with high HBV viral load would encounter poor efficacy in IFN treatment. HBV induced SOCS proteins, which could negatively regulate IFN signaling to decrease IFN therapeutic efficacy, making the expression of SOCS-1 and SOCS-3 proteins in liver before treatment an important impact factor in IFN treatment for CHB. SOCS genes can be the promising candidates in gene therapy and drug development. For example, adenovirus vector expressing the SOCS proteins can be used to treat rheumatic arthritis [31]. Moreover, RNA interference and antisense nucleic acid could also be used to down-regulate the SOCS expression, and some molecular compound could be used to enhance or block its inhibition of the cytokine signaling transduction [32]. New drugs for the JAK-STATs pathway can be developed if detailed mechanism by which SOCS proteins function under physiological and pathological condition is understood. Anti-cytokine and anti-SOCS proteins therapies might be the alternative opportunities for patients with IFN resistance.

\section{Competing interests}

The contents are solely the responsibility of the authors and do not necessarily represent the views of the funding source. The authors declare that they have no competing interests.

\section{Authors' contributions}

$\mathrm{TH}$ conceived the study, provided fund support and revised the manuscript critically for important intellectual content. DLY, CYL, CEQ, CX and LL made substantial contributions to experiment, clinical studies and data analysis. DLY and CYL participated in interpretation of data and manuscript preparation. DLY draft the manuscript and revised it according to all author's opinions. All authors have read and approved the final manuscript.

\section{Acknowledgements}

This study was supported by grants from 973 Project of China (No. 2013CB911300) and National Natural Science Foundation of China (No. 81071363). We present our special thanks to Prof. Alan McLachlan for plasmid pHBV4.1-DNA. We also thank Ms. Cong Liu and Mr. Dongbo Wu for their hard work on scoring the liver tissue sections.

Received: 28 August 2013 Accepted: 6 March 2014 Published: 17 March 2014

\section{References}

1. Lau GK, Piratvisuth T, Luo KX, Marcellin P, Thongsawat S, Cooksley G, Gane E, Fried MW, Chow WC, Paik SW, Lau GK, Piratvisuth T, Luo KX, Marcellin P, Thongsawat S, Cooksley G, Gane E, Fried MW, Chow WC, Paik SW, Chang WY, Berg T, Flisiak R, McCloud P, Pluck N: Peginterferon Alfa-2a, lamivudine, and the combination for HBeAg-positive chronic hepatitis B. N Engl J Med 2005, 352:2682-2695.

2. EASL is short for European Association For The Study Of The Liver: EASL Clinical Practice Guidelines: management of chronic hepatitis B. J Hepatol 2009, 50:227-242.

3. Hoofnagle JH, Doo E, Liang TJ, Fleischer R, Lok AS: Management of hepatitis B: summary of a clinical research workshop. Hepatology 2007, 45:1056-1075. 
4. Fried MW, Piratvisuth T, Lau GKK, Marcellin P, Chow WC, Cooksley G, Luo KX, Paik SW, Liaw YF, Button P, Popescu M: HBeAg and hepatitis B virus DNA as outcome predictors during therapy with peginterferon alfa-2a for HBeAg-positive chronic hepatitis B. Hepatology 2008, 47:428-434.

5. Flink HJ, van Zonneveld M, Hansen BE, de Man RA, Schalm SW, Janssen HL: Treatment with Peg-interferon alpha-2b for HBeAg-positive chronic hepatitis B: HBsAg loss is associated with HBV genotype. Am J Gastroenterol 2006, 101:297-303.

6. Platanias LC: Mechanisms of type-I- and type-II-interferon-mediated signalling. Nat Rev Immunol 2005, 5:375-386.

7. Radaeva S, Jaruga B, Hong F, Kim WH, Fan S, Cai H, Strom S, Liu Y, El-Assal O, Gao B: Interferon-alpha activates multiple STAT signals and down-regulates c-Met in primary human hepatocytes. Gastroenterology 2002, 122:1020-1034.

8. Stark GR: How cells respond to interferons revisited: From early history to current complexity. Cytokine Growth F R 2007, 18:419-423.

9. Starr R, Willson TA, Viney EM, Murray LJL, Rayner JR, Jenkins BJ, Gonda TJ, Alexander WS, Metcalf D, Nicola NA, Hilton DJ: A family of cytokine-inducible inhibitors of signalling. Nature 1997, 387:917-921

10. Naka T, Narazaki M, Hirata M, Matsumoto T, Minamoto S, Aono A, Nishimoto N, Kajita T, Taga T, Yoshizaki K, Naka T, Narazaki M, Hirata M, Matsumoto T, Minamoto S, Aono A, Nishimoto N, Kajita T, Taga T, Yoshizaki K, Akira S, Kishimoto T: Structure and function of a new STAT-induced STAT inhibitor. Nature 1997, 387:924-929.

11. Endo TA, Masuhara M, Yokouchi M, Suzuki R, Sakamoto H, Mitsui $K$, Matsumoto A, Tanimura S, Ohtsubo M, Misawa H, Endo TA, Masuhara M, Yokouchi M, Suzuki R, Sakamoto H, Mitsui K, Matsumoto A, Tanimura S, Ohtsubo M, Misawa H, Miyazaki T, Leonor N, Taniguchi T, Fujita T, Kanakura Y, Komiya S, Yoshimura A: A new protein containing an $\mathrm{SH} 2$ domain that inhibits JAK kinases. Nature 1997, 387:921-924.

12. Flowers LO, Johnson HM, Mujtaba MG, Ellis MR, Haider SMI, Subramaniam PS: Characterization of a peptide inhibitor of janus kinase 2 that mimics suppressor of cytokine signaling 1 function. J Immunol 2004, 172:7510-7518.

13. Grungreiff K, Reinhold D, Ansorge S: Serum concentrations of sIL-2R, IL-6, TGF-beta 1 neopterin, and zinc in chronic hepatitis $C$ patients treated with interferon-alpha. Cytokine 1999, 11:1076-1080.

14. Malaguarnera M, DiFazio I, Laurino A, Ferlito L, Romano M, Trovato BA: Serum interleukin 6 concentrations in chronic hepatitis $C$ patients before and after interferon-alpha treatment. Int J Clin Pharm Th 1997, 35:385-388.

15. Sobue S, Nomura T, Ishikawa T, Ito S, Saso K, Ohara H, Joh T, Itoh M, Kakumu S: Th1/Th2 cytokine profiles and their relationship to clinical features in patients with chronic hepatitis $C$ virus infection. J Gastroenterol 2001, 36:544-551.

16. Tang H, McLachlan A: Transcriptional regulation of hepatitis $B$ virus by nuclear hormone receptors is a critical determinant of viral tropism. ProC Natl Acad Sci U S A 1841-1846, 2001:98.

17. Tang H, McLachlan A: A pregenomic RNA sequence adjacent to DR1 and complementary to epsilon influences hepatitis $B$ virus replication efficiency. Virology 2002, 303:199-210.

18. Gao Z, Liu FJ, Liu L, Zhou TY, Lei J, Xu L, Liu C, Dai J, Chen EQ, Tang H: Application of hepatitis $B$ virus replication mouse model. World J Gastroenterol 1979-1985, 2010:16.

19. Liu FW, Wu DB, Chen EQ, Liu C, Liu L, Chen SC, Gong DY, Zhao LS, Tang H, Zhou TY: Expression of TRAIL in liver tissue from patients with different outcomes of HBV infection. Clin Res Hepatol Gastroenterol 2013, 37:269-274.

20. Bode JG, Ludwig S, Ehrhardt C, Albrecht U, Erhardt A, Schaper F, Heinrich PC, Haussinger D: IFN-alpha antagonistic activity of HCV core protein involves induction of suppressor of cytokine signaling-3. FASEB J 2003, 17:488-490.

21. Lin W, Choe WH, Hiasa Y, Kamegaya Y, Blackard JT, Schmidt EV, Chung RT: Hepatitis $C$ virus expression suppresses interferon signaling by degrading STAT1. Gastroenterology 2005, 128:1034-1041.

22. Koziel MJ: Cytokines in viral hepatitis. Semin Liver Dis 1999, 19:157-169.

23. Hong F, Nguyen VA, Gao B: Tumor necrosis factor alpha attenuates interferon alpha signaling in the liver: involvement of SOCS3 and SHP2 and implication in resistance to interferon therapy. FASEB J 2001, 15:1595-1597.

24. Bock CT, Toan NL, Koeberlein B, Song Le H, Chin R, Zentgraf H, Kandolf R, Torresi J: Subcellular mislocalization of mutant hepatitis B $\mathrm{X}$ proteins contributes to modulation of STAT/SOCS signaling in hepatocellular carcinoma. Intervirology 2008, 51:432-443.
25. Ko E, Kim SJ, Joh JW, Park CK, Park J, Kim DH: CpG island hypermethylation of SOCS-1 gene is inversely associated with $\mathrm{HBV}$ infection in hepatocellular carcinoma. Cancer Lett 2008, 271:240-250.

26. Formeister EJ, Tsuchiya M, Fujii H, Shpyleva S, Pogribny IP, Rusyn I: Comparative analysis of promoter methylation and gene expression endpoints between tumorous and non-tumorous tissues from HCV-positive patients with hepatocellular carcinoma. Mutat Res 2010, 692:26-33.

27. Koeberlein B, Zur Hausen A, Bektas N, Zentgraf $H$, Chin R, Nguyen LT, Kandolf R, Torresi J, Bock CT: Hepatitis B virus overexpresses suppressor of cytokine signaling-3 (SOCS3) thereby contributing to severity of inflammation in the liver. Virus Res 2010, 148:51-59.

28. Simon K, Rotter K, Zalewska M, Gladysz A: HBV-DNA level in blood serum as a predictor of good response to therapy with interferon-alpha- $2 \mathrm{~b}$ of patients with chronic hepatitis B. Med Sci Monit 2000, 6:971-975.

29. Kao JH, Chen PJ, Lai MY, Chen DS: Hepatitis B genotypes correlate with clinical outcomes in patients with chronic hepatitis B. Gastroenterology 2000, 118:554-559.

30. Xu Y, Hu Y, Shi B, Zhang X, Wang J, Zhang Z, Shen F, Zhang Q, Sun S, Yuan Z: HBsAg inhibits TLR9-mediated activation and IFN-alpha production in plasmacytoid dendritic cells. Mol Immunol 2009, 46:2640-2646.

31. Isomaki $P$, Alanara $T$, Isohanni $P$, Lagerstedt A, Korpela M, Moilanen T, Visakorpi T, Silvennoinen O: The expression of SOCS is altered in rheumatoid arthritis. Rheumatology (Oxford) 2007, 46:1538-1546.

32. Takahashi Y, Kaneda H, Takasuka N, Hattori K, Nishikawa M, Watanabe $Y$, Takakura Y: Enhancement of antiproliferative activity of interferons by RNA interference-mediated silencing of SOCS gene expression in tumor cells. Cancer Sci 2008, 99:1650-1655.

doi:10.1186/1743-422X-11-51

Cite this article as: Du et al.: Correlation between the suppressor of cytokine signaling- 1 and 3 and hepatitis B virus: possible roles in the resistance to interferon treatment. Virology Journal 2014 11:51.

\section{Submit your next manuscript to BioMed Central and take full advantage of:}

- Convenient online submission

- Thorough peer review

- No space constraints or color figure charges

- Immediate publication on acceptance

- Inclusion in PubMed, CAS, Scopus and Google Scholar

- Research which is freely available for redistribution 